\title{
Realistic Fe simulation of foldcore sandwich structures
}

\author{
Sebastian Fischer
}

\begin{abstract}
Background: Foldcore is an origami-like structural sandwich core which is manufactured by folding a planar base material into a three dimensional structure. The manufacturing technology is open to a variety of base materials and also a range of unit cell geometries is feasible. This results in a wide spectrum of mechanical properties which can be achieved by foldcores.

Methods: Mechanical characterisation of foldcores by testing is therefore costly. So FE simulation is required to reduce testing effort. A modelling method for foldcores which allows realistic simulation is developed and presented within this paper.

Results: The modelling method is validated by comparison with experiments. The test cases are compression tests and shear tests. Stiffness and strength is evaluated from experiment and simulation. Comparison shows very good correlation.

Conclusions: The presented method is able to simulate the mechanical properties of foldcores and is therefore a valuable tool for further product development.
\end{abstract}

Keywords: Foldcore; Mechanical properties; Finite element analysis (FEA); Mechanical testing

\section{Background}

Sandwich structures generally exhibit an excellent bending stiffness at low weights. The bending stiffness to weight ratio of a panel can be increased by several magnitudes if a monolithic structure is substituted by a sandwich structure. On the other hand, sandwich structures suffer several drawbacks, which limit their use in certain applications. For example in a passenger aircraft, sandwich structures are only used in secondary structures. Secondary structures are characterized by the fact that their failure does not lead to a catastrophic damage to the aircraft. Typical secondary structures are for example flaps, radomes, and nacelle structures. An exception is the fuselage of the Premier Beechcraft I, where sandwich structures are applied.

These disadvantages mentioned above are among others the vulnerability to impact loads which may cause debonding of the face sheet from the core and the problem of humidity accumulation in closed-cell sandwich cores. Novel

Correspondence: sfischer@ifb.uni-stuttgart.de; sebastian-fischer@web.de Institut für Flugzeugbau (IFB), Universität Stuttgart, Pfaffenwaldring 31, 70569 Stuttgart, Germany folded sandwich core materials-fold-core-can solve the problem of humidity accumulation by featuring an open cellular design which enables ventilation of the foldcore (Miura 1972; Miura 1975; Zakirov et al. 2005; Zakirov et al. 2006; Kolax 2004; Kehrle \& Kolax 2006; Hachenberg et al. 2003). So, the foldcore is an interesting alternative sandwich core material to foam cores and honeycomb. To unlock the potential of mechanical properties and help designing the foldcore's unit cell to specific needs, simulation methods have to be used. A modelling method which allows realistic simulation is presented in this paper.

\section{The foldcore concept}

A foldcore is a three-dimensional origami-like structure which is manufactured by folding a planar base material into a three-dimensional structure, as shown in Fig. 1. During the fabrication process, first, the folding edges are embossed onto the sheet-like base material, and afterwards, it is folded along these edges. The folding step can be performed manually or cost-efficiently in a continuous process (Kehrle \& Drechsler 2004).

\section{实}




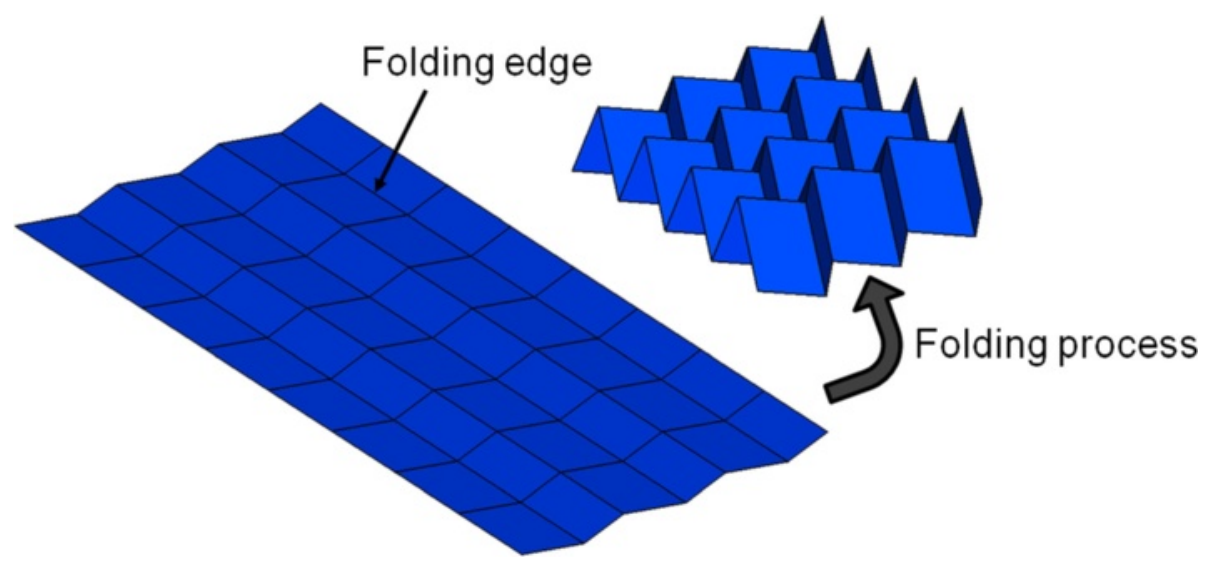

Fig. 1 Flat base material (left) and folded unit cells (right)

A range of base materials is usable for the manufacturing process. Typical base materials are thin metal foils, plastic foils, or resin-impregnated paper-like materials compounded from synthetic or natural fibres.

A foldcore consists of an arrangement of several unit cells. Besides other possible unit cell geometries, the zigzag unit cell as shown in Fig. 1 is suggested for structural applications (Klett \& Drechsler 2007). The zigzag unit cell has four independent geometry parameters which are shown in Fig. 2. These geometry parameters can be adjusted in order to meet requirements like core height or core density for a given application.

It is also possible to use different unit cells inside one foldcore panel while the panel is still producible in one piece (Klett 2013). Figure 3 shows variations in density and in height for a foldcore. Variations in height may be necessary to adjust the core to surrounding geometry. Locally increased density could be used to realize load introduction where locally decreased density can be used to design a predetermined breaking point (Sturm \& Kehrle 2010).

Another way of adjusting the foldcore to specific needs is variation of the base material. The range is from cheap materials like cardboard over metal foils and plastic foils up to high-performance materials like fibre-reinforced materials (Grzeschik et al. 2011; Kilchert et al. 2008; Fischer \& Drechsler 2009; Fischer et al. 2009; Fischer \& Drechsler 2008).

Due to the variability in unit cell geometry and base material, characterization of the foldcore mechanical properties by mechanical testing is expensive. So, simulation methods are needed to support product development.

\section{Simulation of foldcore structures}

Little literature is available on simulation of foldcores. An extensive overview of available literature is given in (Heimbs 2013) which is recommended for further reading. Here, a few of these are picked out to demonstrate modelling methods.

Usually, the meso-structure of the foldcore is considered when finite element (FE) models of the core are set up. This means that the cell walls of the foldcore are meshed with appropriate finite elements. Mostly conventional shell elements are used for this purpose. The meso-structure of a foldcore or a honeycomb can be considered as a thinwalled structure, so shell elements are efficient. Using continuum (solid) elements would lead to a large number of elements and long calculation times.

These meso-models can be used to calculate any given load case. Recent studies dealt with simulation of impact
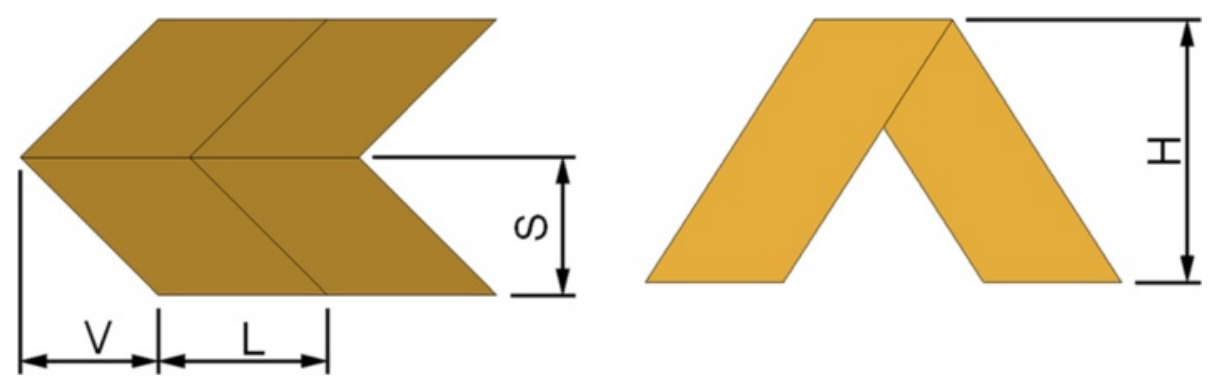

Fig. 2 Independent geometry parameters of foldcore unit cells, top view (left) and side view (right) 


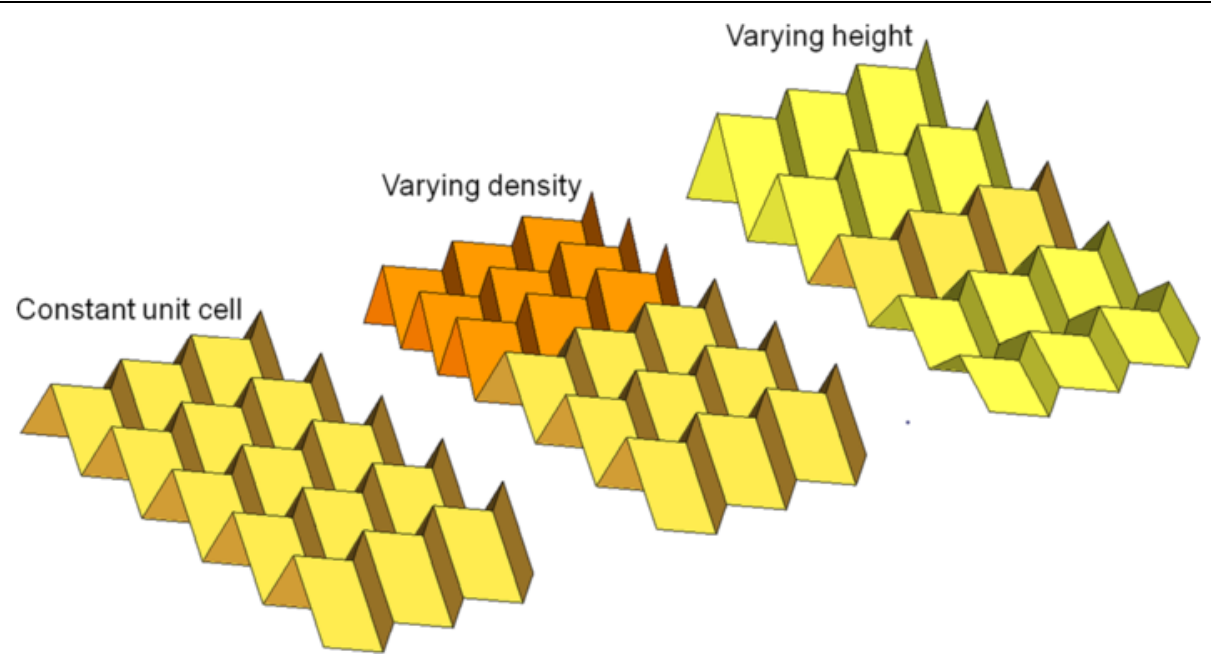

Fig. 3 A sample with a constant zigzag unit cell (left), a sample with varying densities (middle), and a sample with varying heights (right)

load cases (Heimbs et al. 2008; Heimbs et al. 2007). For impact simulation, it is important to capture the crushing behaviour and energy absorption. So, a material model for the cell wall material with a realistic failure model is needed. A detailed modelling of details of the foldcore like geometric imperfections or the bond line in contrast is here not necessary. But these details drive stiffness and strength properties of the foldcore which will be discussed later.

Similar modelling is widely used for honeycomb structures like presented in Hohe (2003), Chawla et al. (2003), Aminanda et al. (2007), and Aktay et al. (2007). As both are thin-walled structures when regarding the meso-structure, similar effects occur during stressing these structures like buckling of the cell walls and crushing and rupture of the cell wall material. So, when working on foldcores, it is reasonable to adopt simulation methods which were developed for honeycombs.

For the design engineer, the most important mechanical properties of a sandwich core material are stiffness and strength. Recent studies focussed on impact behaviour and achieved excellent results in terms of crushing behaviour and energy absorption. But these models typically overpredict initial stiffness of the core and also strength which is defined as peak stress. So, still a modelling method is needed which allows exact prediction of strength and stiffness.

In this study, a modelling method is presented which is able to predict stiffness and strength parameters of foldcores. Influencing variables on the foldcore mechanical

Table 1 Base material data

\begin{tabular}{llllllll}
\hline Material & $E$ & $t$ & $v$ & $\sigma_{\mathrm{y}}$ & $\sigma_{\mathrm{u}}$ & $\varepsilon_{\mathrm{F}}$ & $\rho$ \\
& $(\mathrm{MPa})$ & $(\mathrm{mm})$ & $(-)$ & $(\mathrm{MPa})$ & $(\mathrm{MPa})$ & $(-)$ & $\left(\mathrm{kg} / \mathrm{m}^{3}\right)$ \\
\hline $\begin{array}{l}\text { Aluminium EN } \\
\text { AW-1050A }\end{array}$ & 68,628 & 0.1 & 0.306 & 108.3 & 148.1 & 0.0969 & 2,583 \\
\hline
\end{tabular}

properties are quantified, and modelling methods are presented which can cope with those influences. The modelling method is validated on test cases. Performed tests are flatwise compression and transverse shear (ASTM C273/ C273M-11A 2011; ASTM C365/C365M-11 2011). These tests are typically performed to characterize sandwich core materials.

\section{Unit cell and base material}

The base material used in this study is aluminium EN AW-1050, a pure aluminium with very little alloying constituents. The foil thickness is $0.1 \mathrm{~mm}$. Material data is given in Table 1. During foldcore tests, the material undergoes plasticization and rupture. So, besides Young's modulus $E$, Poisson's ratio $v$, and density $\rho$, yield stress $\sigma_{\mathrm{y}}$, strength $\sigma_{\mathrm{u}}$, and failure strain $\varepsilon_{\mathrm{F}}$ are needed input data for simulation. These material data were determined in tensile tests.

The geometry parameters of the zigzag unit cell used in this study is given in Table 2. The homogenized core density $\rho$ is defined as usual for sandwich core materials. Figure 4 shows a foldcore used in this study.

A set of samples is built and tested in flatwise compression and transverse shear. Due to unit cell geometry, foldcores show an orthotropic behaviour. So, the transverse shear test has to be performed in both directions of the core: L- and W-directions as shown in Fig. 4. The test setup is shown in Fig. 5. Test results are given together with simulation results in the section Results and discussion.

\section{Methods}

Building a finite element model which includes all relevant details of the foldcore is the basis for realistic simulation. Besides material data and the unit cell geometry, there are further effects which have to be considered. These are 
Table 2 Dimensions of the unit cell

\begin{tabular}{lllllll}
\hline Geometry & $\begin{array}{l}H \\
(\mathrm{~mm})\end{array}$ & $\begin{array}{l}\mathrm{L} \\
(\mathrm{mm})\end{array}$ & $\begin{array}{l}S \\
(\mathrm{~mm})\end{array}$ & $\begin{array}{l}V \\
(\mathrm{~mm})\end{array}$ & $\begin{array}{l}\rho_{\text {specific }} \\
(1 / \mathrm{mm})\end{array}$ & $\begin{array}{l}\rho \\
\left(\mathrm{kg} / \mathrm{m}^{3}\right)\end{array}$ \\
\hline 182 & 12 & 6.28 & 8.84 & 8.84 & 0.193 & 54 \\
\hline
\end{tabular}

geometric imperfections of the foldcore, the bonding to the face sheets, and the folding edges (Fischer 2012).

\section{General}

A typical model of a foldcore sample is shown in Fig. 6. The model has the same size as the test specimen which means that the FE model and test specimen consist of the same number of unit cells. The load introduction of the FE model is also modelled according to the test setup used for the test specimens.

This is done in order to avoid different boundary conditions between sample and model. A meso-model of the foldcore is used which uses conventional shell elements. Continuum elements are used for the face sheets. Load introduction is done with a rigid element. Details of the meso-model are given in the next sections. The commercial FE software Abaqus/Explicit is used for all simulations in this study. The element size in noncritical areas is $0.4 \times 0.4 \mathrm{~mm}$. The mesh is refined in the edges to an element size of $0.1 \times 0.2 \mathrm{~mm}$. The mesh refinement is performed with quadrangular elements; no triangular elements are used in the model. An elastic-plastic isotropic material model with isotropic hardening and a ductile failure criterion is used. Geometrically and physically nonlinear simulations are carried out.

\section{Imperfections}

Geometric imperfections are found to be a main influence on the behaviour of the foldcore. These imperfections occur during manufacturing of the foldcore in the folding process. In theory, the material is only folded around the folding edges and the surfaces between those edges stay plane. This would work out if the edges were hinges and would have no bending stiffness. In reality, those edges have, dependent on the foregoing embossing process and on the base material itself, some bending stiffness. That is why the surfaces do not stay perfect plane but become curved. This affects stiffness and buckling load of the foldcore and is therefore an influence on mechanical properties and has to be considered.

Different methods to cope with imperfections are presented in literature. One method to impose random imperfections is node shaking or a random deviation in material properties (Kilchert 2013; Heimbs 2008). Another method is superposing the ideal geometry with the first buckling mode for instance (Rejab \& Cantwell 2013). The method proposed here is scanning a sample and using the original geometry as basis for the model (Fischer 2012).

A sample is scanned with the system ATOS by gom which delivers stl data. This data is then reverse engineered to get NURBS surfaces which can be used for meshing. Figure 7 shows schematically the reverse engineering of a set of scanning data.

To quantify the influence of the imperfections, models with and without imperfections are set up and calculated. The stress-strain curves of a compression test are shown in Fig. 8. When using the scanned geometry with imperfections, stiffness decreases by $20 \%$, where strength remains unchanged in this case.

\section{Folding edges}

Another influence on the mechanical properties of the foldcore is the behaviour of the edges. During the folding

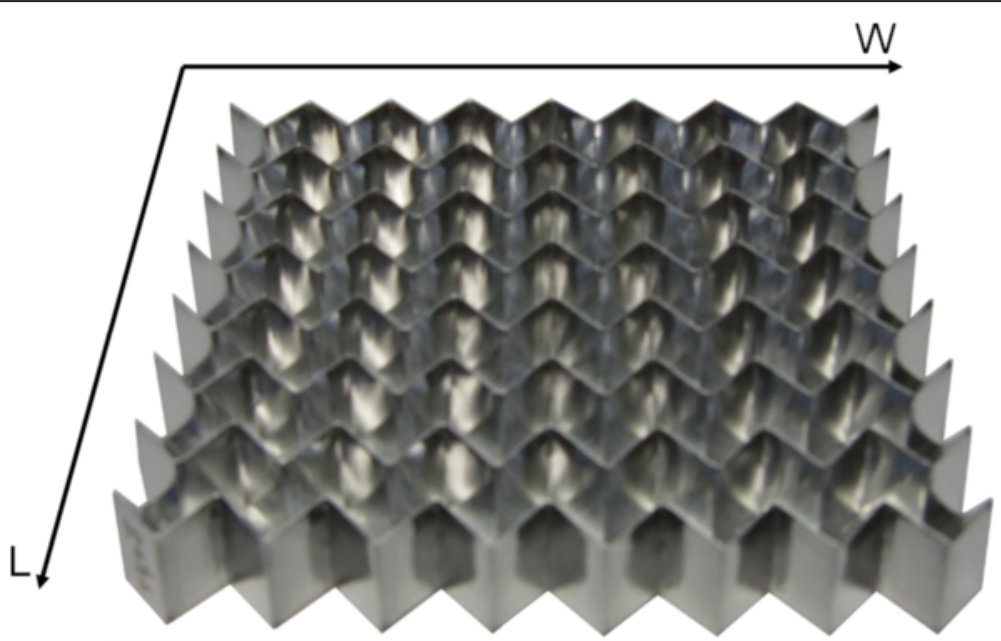

Fig. 4 Aluminium foldcore type 182 

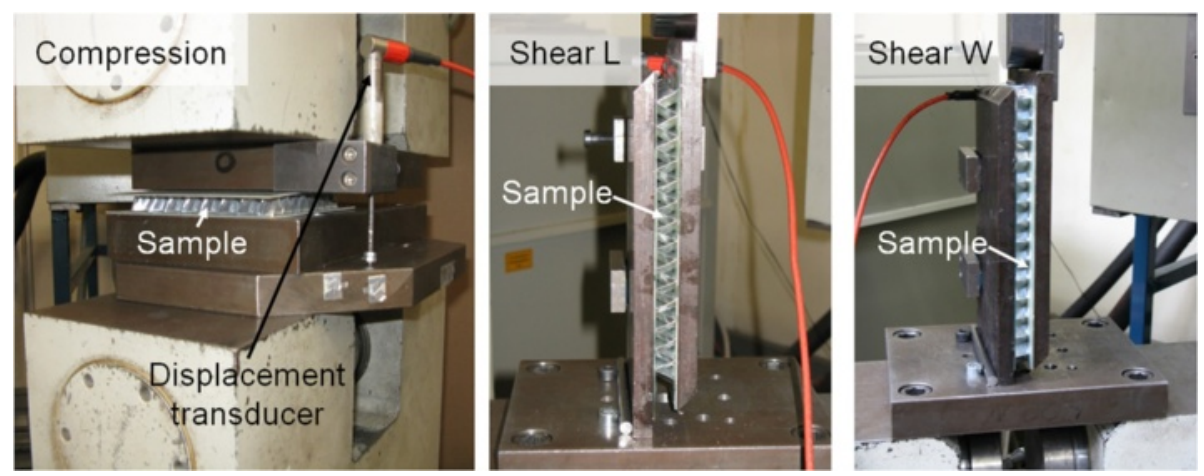

Fig. 5 Test setup for compression (left), shear L (middle), and shear W (right)

process, they are stressed and can be a weak point of the foldcore.

The edges on top and bottom of the core running in the W-direction of the core are not critical. They are bonded to the face sheets and stabilized by the glue. The edges in the L-direction are free and have to be considered in the model.

In the case of aluminium, folding is a cold-forming process. Plasticization occurs which results in partially reduced wall thickness as shown in Fig. 9. Five polished cut images similar to that shown in Fig. 9 are produced. The samples were extracted from different positions of a large foldcore panel. Thickness in the edges is measured and a mean value is calculated. The local thickness of the folding edge is considered in the FE model by using shell elements with reduced thickness. In this study, two elements lie inside the folding edge and they have a constant thickness. The exact thickness distribution inside the folding edge like that shown in Fig. 9 is not represented in the FE mode.

In this study, residual stresses are eliminated by a heat treatment. So, they do not have to be considered. If residual stresses were not eliminated, they could be taken in account by using modified material models for instance.

The mesh size is reduced at the folding edge in order to have at least two elements which are completely inside the edge. Modified material or property data is then assigned to these elements as shown in Fig. 10.

When loading a foldcore, stress concentrations are located inside the edges. So, if the material in the edges is degraded, this is an influence on the global mechanical properties of the foldcore. What happens in this case is that plasticization occurs at reduced loads in the edges. This leads to buckling in the faces and to a reduced strength as buckling is the first failure mechanism of the core. The failure mechanism stays the same but strength is reduced. In the case discussed here, strength is reduced by $13 \%$ under compressive load while stiffness is not affected significantly.

\section{Bonding to face sheets}

The last important influence on the mechanical behaviour is the bonding to the face sheets. The bonding defines the strength against debonding. But also the stiffness and

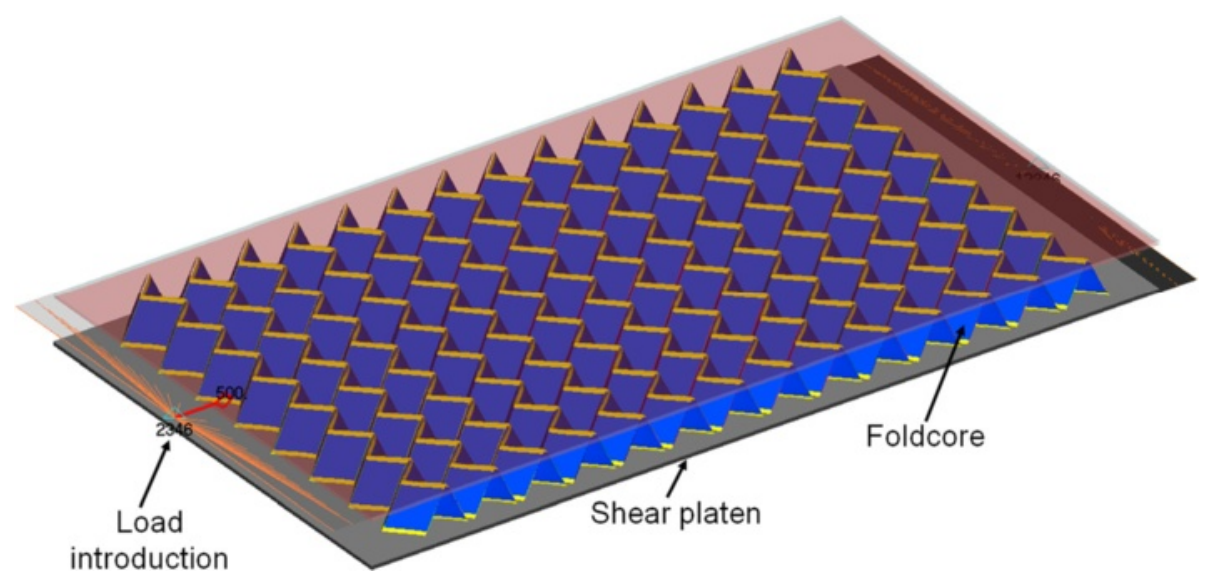

Fig. 6 FE model of foldcore 182 for a transverse shear test (L-direction) 


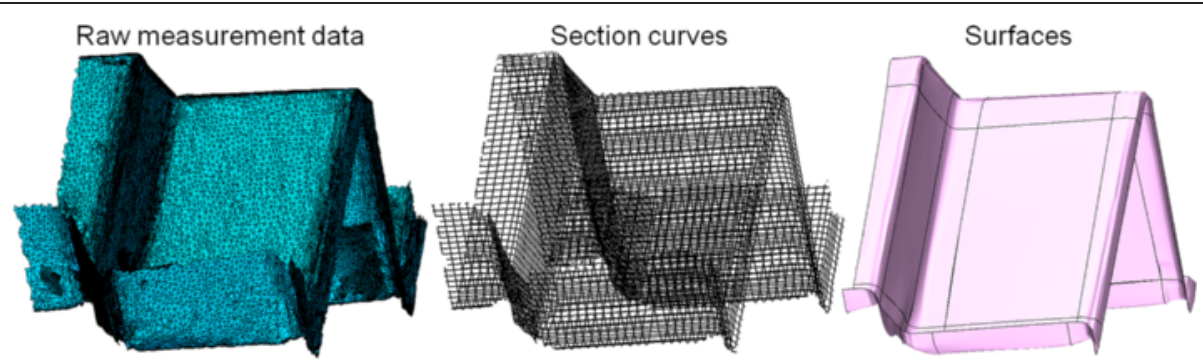

Fig. 7 Processing of scanning data: raw scanning data (left), section curves (middle), reverse-engineered CAD model (right)

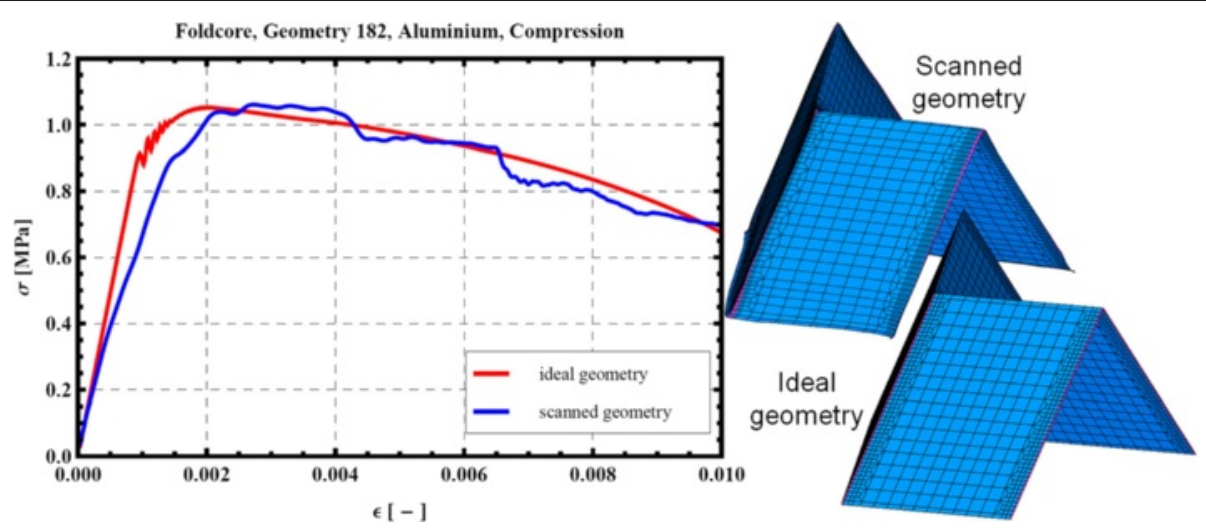

Fig. 8 Stress-strain curves for ideal and scanned geometry, compression test

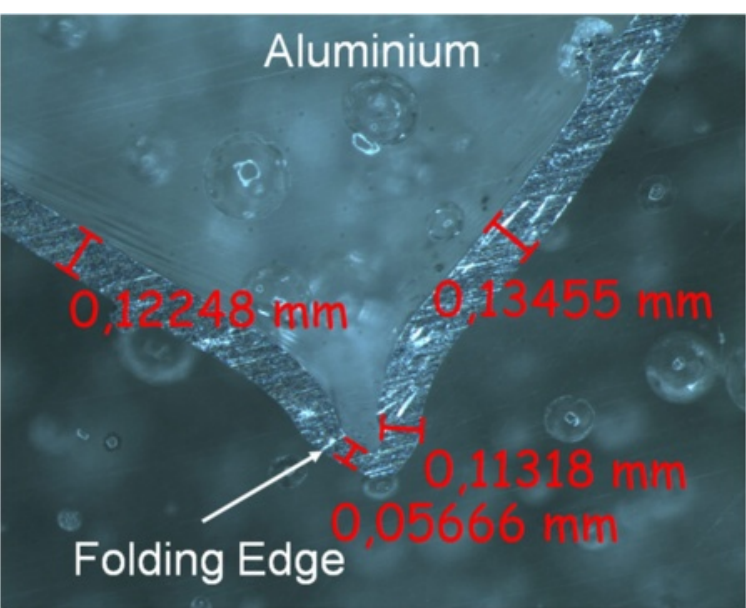

Fig. 9 Folding edge in aluminium foldcore 


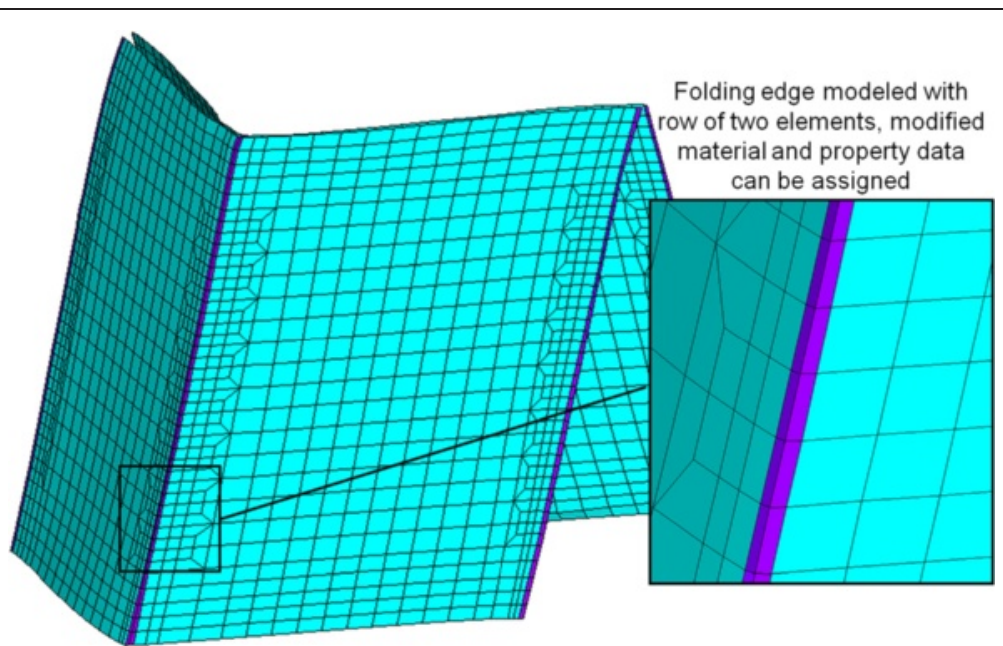

Fig. 10 FE model with folding edge
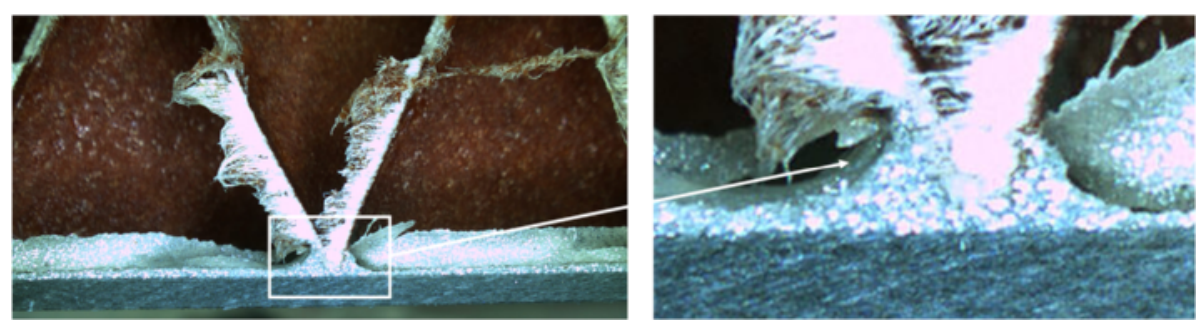

Fig. 11 Bonding of foldcore to face sheets
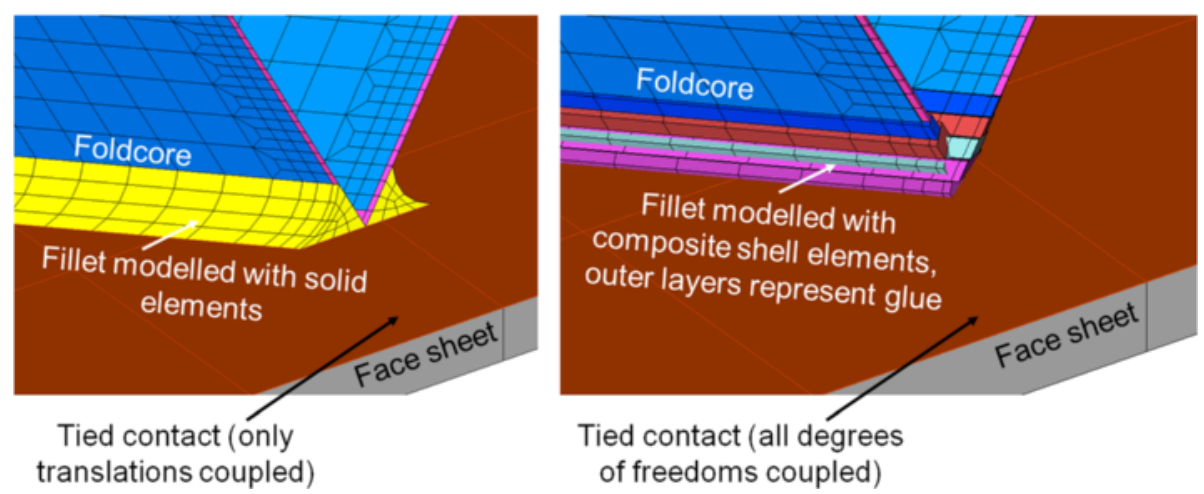

Fig. 12 Modelling of bond line 
Table 3 Thickness of composite shell elements

\begin{tabular}{|c|c|c|c|c|c|}
\hline & & $\begin{array}{l}\text { Row } 1 \\
(\mathrm{~mm}) \\
\end{array}$ & $\begin{array}{l}\text { Row } 2 \\
(\mathrm{~mm}) \\
\end{array}$ & $\begin{array}{l}\text { Row } 3 \\
(\mathrm{~mm}) \\
\end{array}$ & $\begin{array}{l}\text { Row } 4 \\
(\mathrm{~mm})\end{array}$ \\
\hline Layer 1 & Adhesive & 0.043735 & 1.4462 & 0.28185 & 0.50597 \\
\hline Layer 2 & Aluminium & 0.1 & 0.1 & 0.1 & 0.00001 \\
\hline Layer 3 & Adhesive & 0.043735 & 1.4462 & 0.28185 & 0.50597 \\
\hline
\end{tabular}

strength of the core in flatwise compression and transverse shear are influenced by the bonding.

This is due to two effects. First, the bonding is not perfectly rigid but has some compliancy. Second, the glue builds up a fillet which stabilizes the core and increases the buckling load. This is insofar important as the foldcores typically fail by buckling and not by reaching a material limit. Figure 11 shows an example of a fillet.

The fillet could be considered by modelling it with solid elements. This would be realistic but would also bring in additional degrees of freedom which mean additional computational effort. Also, the modelling itself could be expensive if we think of foldcore models based on scanned geometries.

The approach in this study to account for the bonding is to smear the bonding into the shell elements of the foldcore. Composite shell elements are used which have one inner layer for the foldcore base material and two outer layers for the adhesive material. Here, four rows of shell elements are used (see Fig. 12). For the elements which are connected to the face sheets, the inner layer which represents the base material is dropped. So, the stiffness of the connection is only determined by the glue material.

The thickness distribution of the shell elements which represent the glue is shown in Table 3. This region is modelled with four rows of shell elements, so the thickness distribution of the shell elements approximates the shape of the fillet. Several fillets were measured with optical methods to quantify its shape. Mean values were calculated and used for the thickness distribution in Table 3.

The modelling methods shown in Fig. 12 are compared by simulating a test case. Transverse shear is used as the test case. The stress-strain curves are shown in Fig. 13. The course of the curves is similar with a small deviation of $1.1 \%$ in maximum stress. So, both modelling methods are nearly equal in terms of mechanical performance, while the modelling with composite shells is less expensive.

Next comparison is between consideration and negligence of the fillet. Another comparative calculation is carried out. In the first model, the connection between the foldcore and face sheet is realized by a simple tied contact which connects all degrees of freedom. This is the stiffest possible connection between the foldcore and face sheet. But it is easy to model and therefore widely used in literature. In the second model, the connection is realized by a modelled fillet. The model with fillet has a $2.9 \%$ lower stiffness but strength increases by $6.7 \%$. The stress-strain curves are shown in Fig. 14.

\section{Results and discussion}

The modelling details described above are assembled in finite element models which are used to calculate the flatwise compression test and the transverse shear test in order to validate the modelling.

The test setup is shown in Fig. 5. All samples are tested with a universal testing machine. In the compression test, the sample is compressed between two parallel platens. Force is measured with the machine load cell, and displacement is measured with an external displacement transducer. Engineering stress and strain are calculated from force and displacement data as shown in Fig. 16. Strength and modulus are calculated from test data. Strength is defined as peak stress of the stress-strain curve. The modulus is evaluated in the first part of the stress-strain curve where

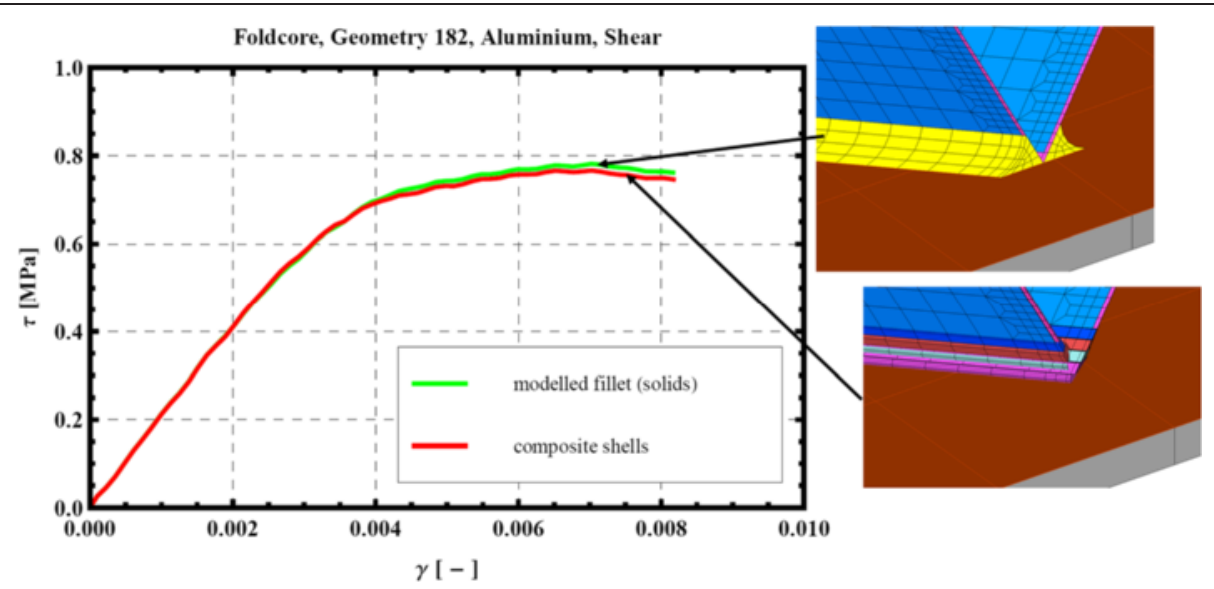

Fig. 13 Modelling of bond line: solid modelling versus shell modelling 


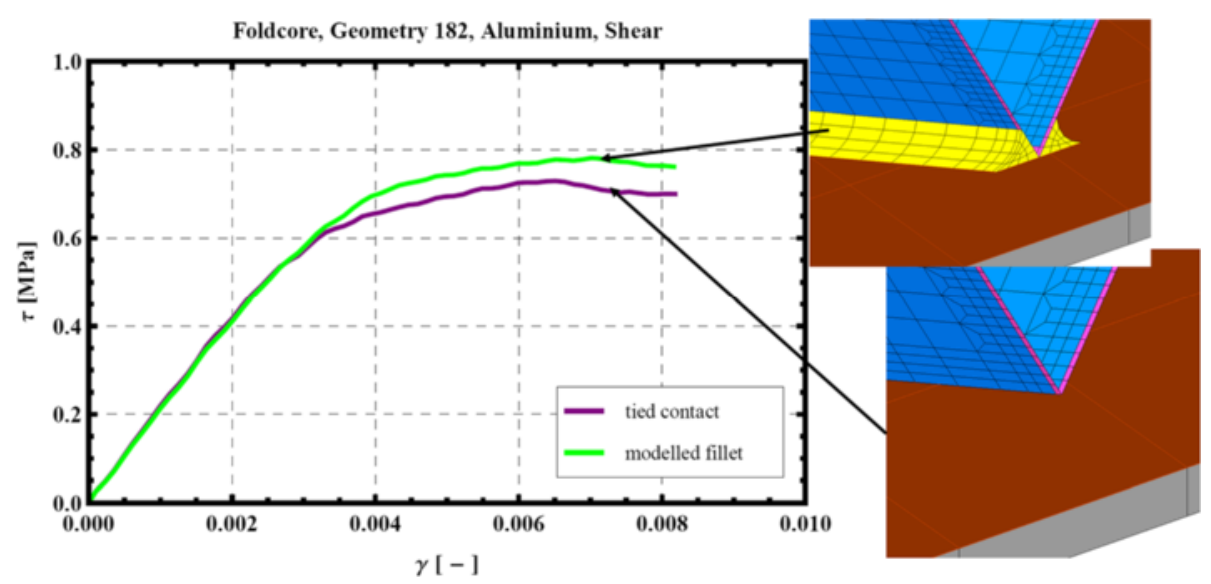

Fig. 14 Tied contact versus modelled bond line

it is fairly linear. Stiffness and strength of the samples are summarized in Table 4. The test setup for the shear tests is similar. The sample is glued on massive steel plates. These steel plates are loaded to introduce transversal shear in the sample. The test has to be performed in the L-direction and W-direction of the sample due to the orthotropy imposed by the unit cell geometry. Stress-strain curves are shown in Fig. 17, and data is collected in Table 4.

The failure modes observed in the experiments are qualitatively the same for compression and shear. The first failure mode is buckling of the cell faces. The main mechanism which drives buckling is plasticization of the folding edge. If this happens, the "clamping" of the faces gets weaker and the critical buckling load of the faces is decreased. Buckling defines the peak stress of the stressstrain curve. At this point, there is no rupture in the material.

The second failure mechanism is the rupture of the folding edge. This happens after reaching peak stress leading to a significant drop in the stress level. The further course of the stress-strain curve is defined by further rupture in the edges, folding of the faces, and compaction.

Six specimens are used for every performed test. As shown in Table 4, there is a large scatter in the experiments. This is due to sample manufacturing; the folding

Table 4 Comparison of test and simulation

\begin{tabular}{llllll}
\hline Test & $\begin{array}{l}\text { Modulus/ } \\
\text { strength }\end{array}$ & \multicolumn{2}{l}{ Experiment } & FEM \\
\cline { 3 - 5 } & & Minimum & Maximum & Mean & \\
\hline Compression & $E_{Z}(\mathrm{MPa})$ & 16 & 58 & 34 & 35 \\
& $\sigma_{Z}(\mathrm{MPa})$ & 0.49 & 0.77 & 0.63 & 0.67 \\
\multirow{2}{*}{ Shear L } & $G_{L}(\mathrm{MPa})$ & 148 & 183 & 160 & 166 \\
& $\tau_{L}(\mathrm{MPa})$ & 0.63 & 0.65 & 0.64 & 0.66 \\
\multirow{2}{*}{ Shear W } & $G_{W}(\mathrm{MPa})$ & 159 & 276 & 202 & 224 \\
& $\tau_{W}(\mathrm{MPa})$ & 0.63 & 0.67 & 0.66 & 0.74 \\
\hline
\end{tabular}

process for these samples is done manually, leading to unequal quality of samples. Automatic production of samples in constant quality is a development target in ongoing research.

These tests are recalculated with the methods described above. An elastic-plastic material model with a ductile failure criterion is used. Material data is given in Table 1. All samples have the same unit cell geometry (tpye 182); the dimensions of the unit cell are given in Table 2.

The model for simulation of the compression test is shown in Fig. 15. It consists of 64 unit cells according to the size of the sample. Stress-strain curves and the FE model are shown in Fig. 16. The modulus is evaluated in the first part of the stress-strain curve before reaching peak stress. The peak stress is taken as strength of the foldcore. Stiffness and strength are given Table 4. Simulation is able to predict the mean values from tests with little deviation.

FE models for the shear test are set up analogous to the model for compression. The model for the test in the L-direction is shown in Fig. 6. The stress-strain curves are given in Fig. 17, and the strength and stiffness in Table 4. Again, the models are able to predict the test values with little deviation.

As seen in "Imperfections," "Folding edges," and "Bonding to face sheets," the new modelling approach does not change the qualitative mechanical behaviour of the foldcores much. But the quantitative comparison to experimental values was improved. So, with this modelling method developed here, it is possible to simulate strength and stiffness with high accuracy.

\section{Conclusions}

A modelling method for realistic simulation of foldcores has been elaborated. The influences on mechanical properties of foldcores were investigated and modelling 


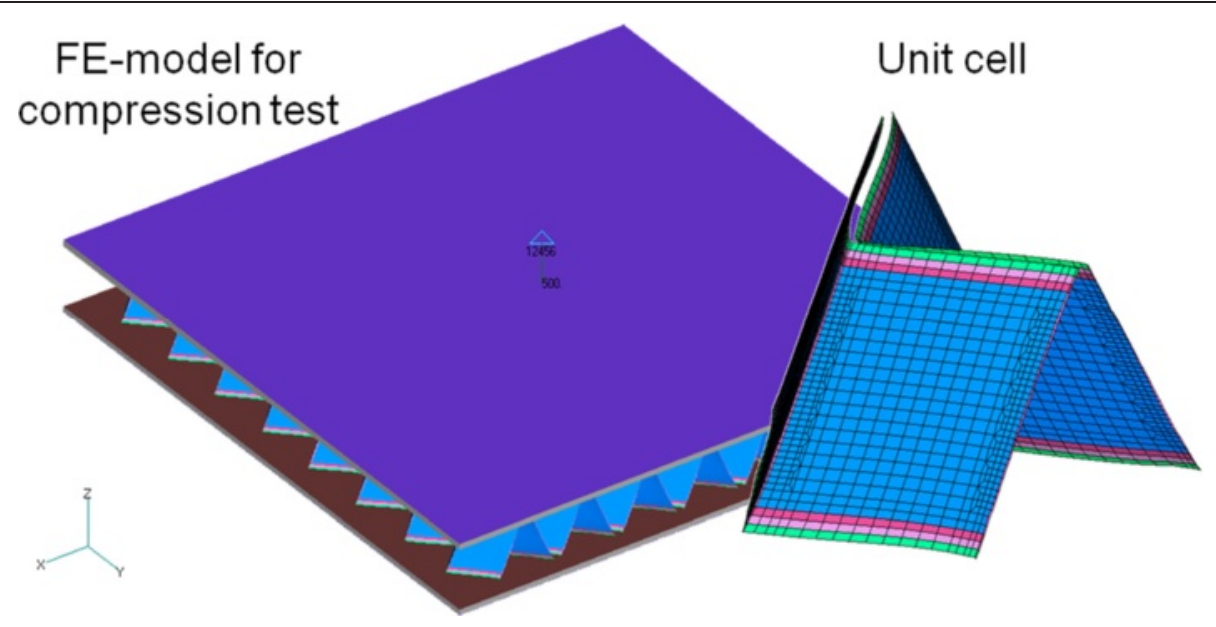

Fig. 15 FE model for compression test
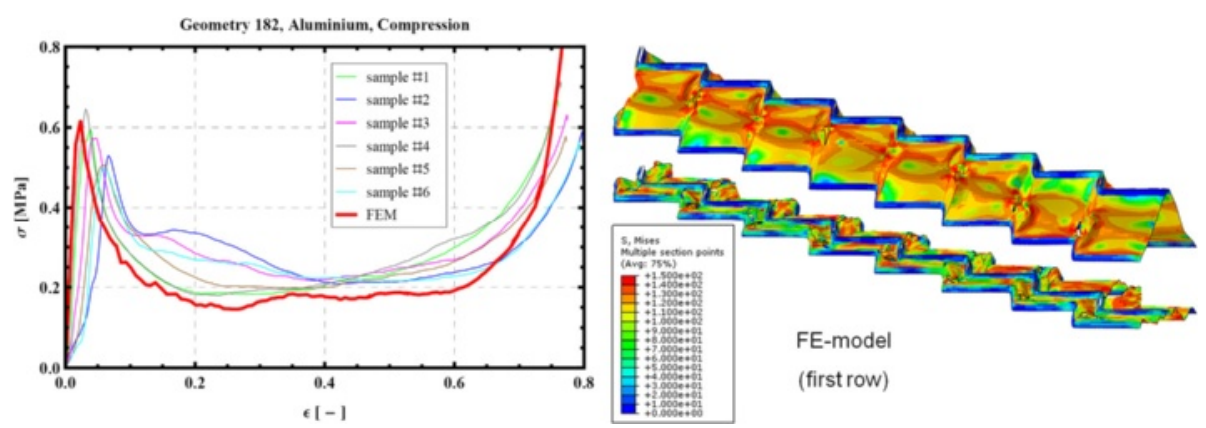

(firstrow)

Fig. 16 Stress-strain curve of compression test and FE model
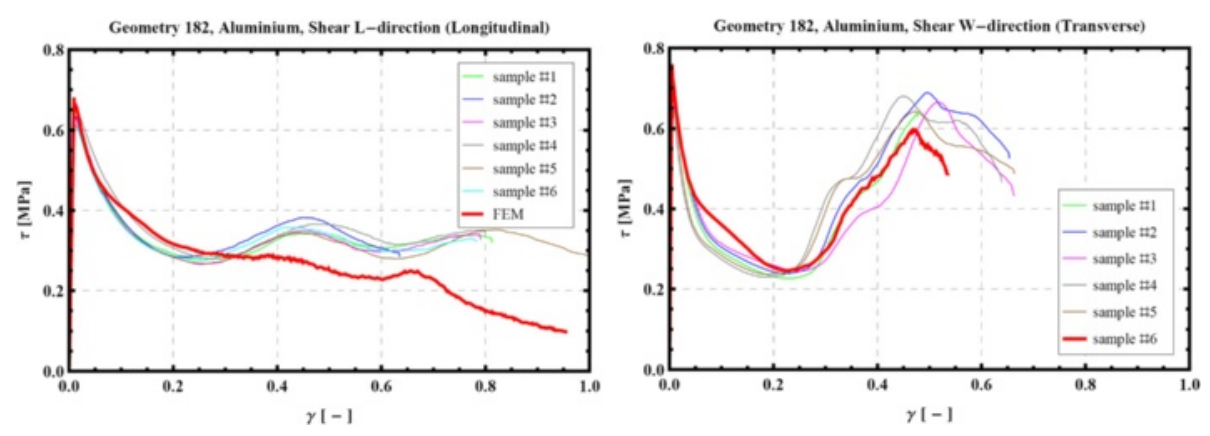

Fig. 17 Stress-strain curves of shear test in the L-direction (left) and the W-direction (right) 
approaches were set up. These influences are geometrical imperfections, the folding edges, and the bond line.

The modelling method was validated by comparison with experiments. Compression tests and shear tests were used as test cases. The models were able to predict test results with little deviation.

\section{Competing interests}

The author declares that he has no competing interests.

\section{Acknowledgements}

Parts of this work were part of the EU project CELPACT within the Sixth Framework Programme of the European Commission (Contract AST5-CT2006-031038, 2006-2009). The author gratefully acknowledges the funding of the research activities.

Received: 13 April 2015 Accepted: 29 June 2015

Published online: 18 July 2015

\section{References}

Aktay, L, Johnson, AF, \& Kröplin, B-H. (2007). Numerical modelling of honeycomb core crush behaviour. Engineering Fracture Mechanics, 75(9), 2616-2630,

Aminanda, Y, Castanié, B, Barrau, J-J, \& Thevenet, P. (2007). Experimental analysis and modeling of the crushing of honeycomb cores. Applied Composite Materials, 12, 213-227.

ASTM C273/C273M-11A (2011) Standard test method for shear properties of sandwich core materials. ASTM International, West Conshohocken PA. www.astm.org.

ASTM C365/C365M-11 (2011) Standard test method for flatwise compressive properties of sandwich cores. ASTM International, West Conshohocken PA. SAMPE. www.astm.org.

Chawla, A, Mukherjee, S, Kumar, D, Nakatani, T, \& Ueno, M. (2003). Prediction of crushing behaviour of honeycomb structures. IJCrash, 8(3), 229-235.

Fischer, S. (2012). Numerische Simulation der mechanischen Eigenschaften von Faltkern-Sandwichstrukturen, phd-thesis. Aachen: Shaker Verlag. ISBN 978-3-8440-1258-3.

Fischer S, \& Drechsler K. (2008). Aluminium foldcores for sandwich structure application, cellular metals for structural and functional applications. Cellmet 2008 (pp. 167-172). Dresden, Germany.

Fischer S, \& Drechsler K (2009). FE-simulation of foldcores made out of resin impregnated aramid fiber paper. SAMPE. Europe 30th International Conference. (pp. 45-55). Paris.

Fischer, S, Drechsler, K, Kilchert, S, \& Johnson, AF. (2009). Mechanical tests for foldcore base material properties. Composites: Part A, 40A(12), 1941-1952.

M. Grzeschik, M. Fach, S. Fischer, Y. Klett, R. Kehrle, K. Drechsler, Isometrically folded high performance core materials. PFAM XIX 2011 - Nineteenth International Symposium on Processing and Fabrication of Advanced Materials Conference, Auckland, New Zealand, 2011.

D. Hachenberg, C. Mudra, M. Nguyen, Folded structures-an alternative sandwich core material for future aircraft concepts. Deutscher Luft- und Raumfahrt Kongress, München, 2003

Heimbs, S. (2008). Sandwichstrukturen mit Wabenkern: Experimentelle und numerische Analyse des Schädigungsverhaltens unter statischer und kurzzeitdynamischer Belastung, Institut für Verbundwerkstoffe $\mathrm{GmbH}$, Kaiserslautern. ISBN 3-934930-73-5.

Heimbs, S. (2013). In S Abrate, B Castanié, \& Y Rajapakse (Eds.), Foldcore sandwich structure and their impact behaviour: an overview, in dynamic failure of composite and sandwich structures. Springer. ISBN 978-94-007-5329-7, Springer Dordrecht Heidelberg, New York, London

S. Heimbs, P. Middendorf, C. Hampf, F. Hähnel, K. Wolf. Aircraft sandwich structures with folded core under impact load. 8th International Conference on Sandwich Structures ICSS 8, SAMPE. Porto, 2008

Heimbs, S, Middendorf, P, Kilchert, S, Johnson, AF, \& Maier, M. (2007). Experimental and numerical analysis of composite folded sandwich core structures under compression. Applied Composite Materials, 14, 363-377.

Hohe, J. (2003). Elastizitätsverhalten von Sandwich-Zellkernen und zweidimensionalen Modellschäumen, Shaker Verlag, Aachen. ISBN 3-8322-2086-0.

Kehrle R, Drechsler K (2004). Manufacturing of folded core structures for technical applications. SAMPE Europe 25th International Conference. (pp. 508-513). Paris.
Kehrle, R, \& Kolax, M. (2006). Sandwich structures for advanced next generation fuselage concepts. SAMPE Europe Technical Conference, Toulouse, September, $13-14,11-16$

S. Kilchert, Nonlinear finite element modelling of degradation and failure in folded core composite sandwich structures. PhD thesis, DLR - Deutsches Zentrum für Luft- und Raumfahrt e.V., Köln, 2013, ISSN 1434-8454

Kilchert, S, Johnson, A F, Voggenreiter H. (2008) Finite element modelling of phenolic resin impregnated aramid paper adopted in foldcore sandwich structures. CST 2008. Civil-Comp Press, paper 316.

Klett, Y. (2013). Auslegung multifunktionaler isometrischer Faltstrukturen für den technischen Einsatz, phd-thesis, Verlag Dr. Hut, München. ISBN 978-3-8439-1025-5.

Y. Klett; K. Drechsler, Design of multifunctional folded core structures for aerospace sandwich applications. Deutscher Luft- und Raumfahrtkongress 2007

Kolax, M. (2004). Concept and technology: advanced composite fuselage structures. JEC Composites, Vol 10, No 6/7.

Miura, K, (1972). Zeta-core sandwich-its concept and realization. Institute of Space and Aeronautical Science. University of Tokyo, Report No. 480

Miura, K. (1975). New structural form of sandwich core. Journal of Aircraft, 12(5), 437-441. doi:10.2514/3.44468.

Rejab, MRM, \& Cantwell, WJ. (2013). The mechanical behaviour of corrugated-core sandwich panels. Composites: Part B, 47, 267-277.

Sturm R, Kehrle R (2010). Crashworthiness aspects of CFRP airframe panels in fold core design. JEC - Forum. Paris.

Zakirov, I. M., Nikitin, A., Akishev, N., Ruckert, C., \& Mudra, C. (2005). Technology research and equipment development for fabrication of folded structure sandwich core from new material. In SAMPE Europe Int Conf, Paris (pp. 429-434).

Zakirov, I M, Nikitin, A, Alexeev, K, \& Mudra, C (2006). Folded structures: performance, technology and production. In SAMPE Europe Int Conf. (pp. 234-239). Paris.

\section{Submit your manuscript to a SpringerOpen ${ }^{\circ}$ journal and benefit from:}

- Convenient online submission

- Rigorous peer review

- Immediate publication on acceptance

- Open access: articles freely available online

- High visibility within the field

- Retaining the copyright to your article

Submit your next manuscript at $\gg$ springeropen.com 